\title{
Article \\ A P-61 Black Widow Inspired Palladium Biladiene Complex for Efficient Sensitization of Singlet Oxygen Using Visible Light
}

\author{
Anthony T. Rice, Glenn P. A. Yap (1) and Joel Rosenthal *(i) \\ Department of Chemistry and Biochemistry, University of Delaware, Newark, DE 19716, USA; \\ atrice@udel.edu (A.T.R.); gpyap@udel.edu (G.P.A.Y.) \\ * Correspondence: joelr@udel.edu; Tel.: +1-302-831-0716
}

Citation: Rice, A.T.; Yap, G.P.A.; Rosenthal, J. A P-61 Black Widow Inspired Palladium Biladiene

Complex for Efficient Sensitization of Singlet Oxygen Using Visible Light. Photochem 2022, 2, 58-68. https:/ / doi.org/10.3390/photochem2010005

Received: 29 November 2021

Accepted: 4 January 2022

Published: 11 January 2022

Publisher's Note: MDPI stays neutral with regard to jurisdictional claims in published maps and institutional affiliations.

Copyright: (C) 2022 by the authors. Licensee MDPI, Basel, Switzerland. This article is an open access article distributed under the terms and conditions of the Creative Commons Attribution (CC BY) license (https:// creativecommons.org/licenses/by/ $4.0 /$ )

\begin{abstract}
Photodynamic therapy (PDT) is a promising treatment option that ablates cancerous cells and tumors via photoinduced sensitization of singlet oxygen. Over the last few decades, much work has been devoted to the development of new photochemotherapeutic agents for PDT. A wide variety of macrocyclic tetrapyrrole based photosensitizers have been designed, synthesized and characterized as PDT agents. Many of these complexes have a variety of issues that pose a barrier to their use in humans, including biocompatibility, inherent toxicity, and synthetic hurdles. We have developed a non-traditional, non-cyclic, and non-aromatic tetrapyrrole ligand scaffold, called the biladiene (DMBil1), as an alternative to these traditional photosensitizer complexes. Upon insertion of a heavy atom such as $\mathrm{Pd}^{2+}$ center, $\mathbf{P d}[\mathbf{D M B i l 1}]$ generates singlet oxygen in substantial yields $\left(\Phi_{\Delta}=0.54, \lambda_{\text {exc }}=500 \mathrm{~nm}\right)$ when irradiated with visible light. To extend the absorption profile for Pd[DMBil1] deeper into the phototherapeutic window, the tetrapyrrole was conjugated with alkynyl phenyl groups at the 2- and 18-positions (Pd[DMBil2-PE]) resulting in a significant redshift while also increasing singlet oxygen generation $\left(\Phi_{\Delta}=0.59,600 \mathrm{~nm}\right)$. To further modify the dialkynyl-biladiene scaffold, we conjugated a 1,8-diethynylanthracene with to the Pd[DMBil1] tetrapyrrole in order to further extend the compound's $\pi$-conjugation in a cyclic loop that spans the entire tetrapyrrole unit. This new compound (Pd[DMBil2-P61]) is structurally reminiscent of the P61 Black Widow aircraft and absorbs light into the phototherapeutic window (600-900 nm). In addition to detailing the solid-state structure and steady-state spectroscopic properties for this new biladiene, photochemical sensitization studies demonstrated that Pd[DMBil2-P61] can sensitize the formation of ${ }^{1} \mathrm{O}_{2}$ with quantum yields of $\Phi_{\Delta}=0.84$ upon irradiation with light $\lambda=600 \mathrm{~nm}$. These results distinguish the Pd[DMBil2-P61] platform as the most efficient biladiene-based singlet oxygen photosensitizer developed to date. When taken together, the improved absorption in the phototherapeutic window and high singlet oxygen sensitization efficiency of Pd[DMBil2-P61] mark this compound as a promising candidate for future study as an agent of photodynamic cancer therapy.
\end{abstract}

Keywords: biladiene; phototherapeutic window; singlet oxygen; Sonogashira coupling; spectroscopic properties; non-aromatic tetrapyrrole

\section{Introduction}

Photodynamic therapy (PDT) is an alternative treatment option for various types of cancers [1,2], whereby a photosensitizer is administered to a patient, and the treatment site is selectively irradiated with light of a particular wavelength [3]. The photosensitizer absorbs the photons and is promoted into an excited electronic state [4]. From this excited state, the complex then undergoes intersystem crossing, flipping the spin of an electron, and entering into an excited triplet state [5]. The energy in that excited triplet state can then be intermolecularly transferred to ground state triplet molecular oxygen $\left({ }^{3} \mathrm{O}_{2}\right)$ [6], resulting in triplet-triplet annihilation. This process returns the photosensitizer to its singlet ground state, while promoting molecular oxygen into an excited singlet state $\left({ }^{1} \mathrm{O}_{2}\right)$ [7]. Singlet oxygen is a potent reactive oxygen species (ROS) that can readily oxidize organic matter [8]. 
For this therapy, the ROS causes oxidative damage to various organelles inside the cell, ultimately leading to cellular death, preferentially via apoptosis rather than necrosis $[9,10]$.

Much research has gone into developing new photosensitizers for PDT against cancer [11-13], microbes/viruses [14-16], and for various dermatological applications [17]. Many of these complexes are comprised of cyclic, aromatic tetrapyrroles that absorb strongly in the phototherapeutic window (600-900 nm) [18-20]. Within this arena, our laboratory and others have actively developed non-traditional tetrapyrroles that contain a single tetrapyrrole, with an $s p^{3}$-hybridized meso-carbon for applications in photomedicine and catalysis. Some platforms of interest include 10,10-dimethylphlorins [21-29] and 10,10-dimethylisocorroles [30-35], however, the most attractive alternative platforms we have prepared and studied for PDT applications have been new oligotetrapyrrole complexes based upon a 10,10-dimethyl-5,15-dipentfluorophenylbiladiene (DMBil1) core [36]. The DMBil1 architecture is a linear oligotetrapyrrole, with an $s p^{3}$ hybridized meso-carbon at the 10-position. This freebase tetrapyrrole absorbs light as far red as $500 \mathrm{~nm}$ with minimal singlet oxygen generation $\left(\Phi_{\Delta}=0.015\right)$, however, metalation of DMBil1 with $\mathrm{Pd}^{2+}$ to invoke the heavy atom effect [37], induces enhanced intersystem crossing (ISC) through improved spin orbit coupling [38]. Accordingly, the parent biladiene bound to $\mathrm{Pd}^{2+}$ (Pd[DMBil1]) showed a modest redshift in absorption to $\sim 550 \mathrm{~nm}$, and high ISC efficiency and excited state triplet lifetimes on the order of 15-30 $\mu$ s [39]. These altered photophysics result in improved quantum yields for sensitization of singlet oxygen as Pd[DMBil1] supports $\Phi_{\Delta}=0.54$, upon excitation at $550 \mathrm{~nm}$. Water solubilization of Pd[DMBil1] and related derivatives showed that the biladiene construct is well tolerated by triple-negative breast cancer cell lines in culture [40]. Irradiation of Pd[DMBil1] [40] as well as Pd[DMBil1]-(gold nanoshell) conjugates [41,42] within TNBC cells demonstrated that these architectures provide an exceptionally high phototoxicity index $(P I=5300)$, and preferentially phototrigger cell death via apoptotic pathways. To date, the main limitation of the Pd[DMBil1] framework for PDT applications is its lack of absorption in the phototherapeutic window of light $(600-900 \mathrm{~nm})$ that most deeply penetrates biological tissues.

Recent work has aimed at modifying the biladiene periphery to drive the tetrapyrroles absorbance profile to the long end of the visible region. In recent work, regioselective bromination of Pd[DMBil1] at the 2- and 18-positions to deliver Pd[DMBilBr 2 ] followed by Sonogashira coupling with aryl alkynes provided a series of biladienes with extended $\pi$-systems (see Figure 1 and Scheme 1) [43]. An extended biladiene variant bearing phenylalkyne based moieties at the 2- and 18-positions was shown to absorb light out to $\sim 650 \mathrm{~nm}$ and sensitized the formation of ${ }^{1} \mathrm{O}_{2}$ with an improved quantum yield of $\Phi_{\Delta} \sim 0.6$. The basic structural motif of the phenyl-alkyne appended biladiene provides a conceptual opportunity for additional modification. As shown in Figure 1, the addition of an unsaturated linker between the ancillary phenyl groups would form a $\pi$-conjugated bridge that spans both of the dipyrrin units that comprise the biladiene architecture. This structure, which is structurally reminiscent of the Northrop P-61 Black Widow aircraft, places a 1,8-disubstituted anthracene across the biladiene's alkyne appendages, giving rise to an extended macrocyclic framework that remains non-aromatic. We hypothesized that the installation of the anthracenyl diyne unit would serve to buttress the biladiene core and provide much greater rigidity to the oligotetrpyrrole scaffold. We envisioned that this structural reinforcement could improve the complex's triplet excited-state lifetime and engereder a higher $\Phi_{\Delta}$ than had been observed for previously studied biladienes.

Herein, we report an concise synthetic route to the Pd[DMBil2-P61] complex, which is also subjected to full structural and steady state spectroscopic analysis. These results demonstrate that this new biladiene bearing a dialkynylanthracene bridge at the 2- and 18- pyrrole positions can absorb light in the phototherapeutic window and supports a triplet photochemistry that can be leveraged for PDT and other applications. Additional experiments also demonstrate that Pd[DMBil2-P61] is by far the most efficient biladienebased photosensitizer for ${ }^{1} \mathrm{O}_{2}$ that has been prepared and studied to date. The exceptional ability of Pd[DMBil2-P61] to sensitize the formation of ${ }^{1} \mathrm{O}_{2}$ may well be due to its relatively 
rigid, macrocyclic structure, which is unique among palladium biladiene complexes studied prior this work.
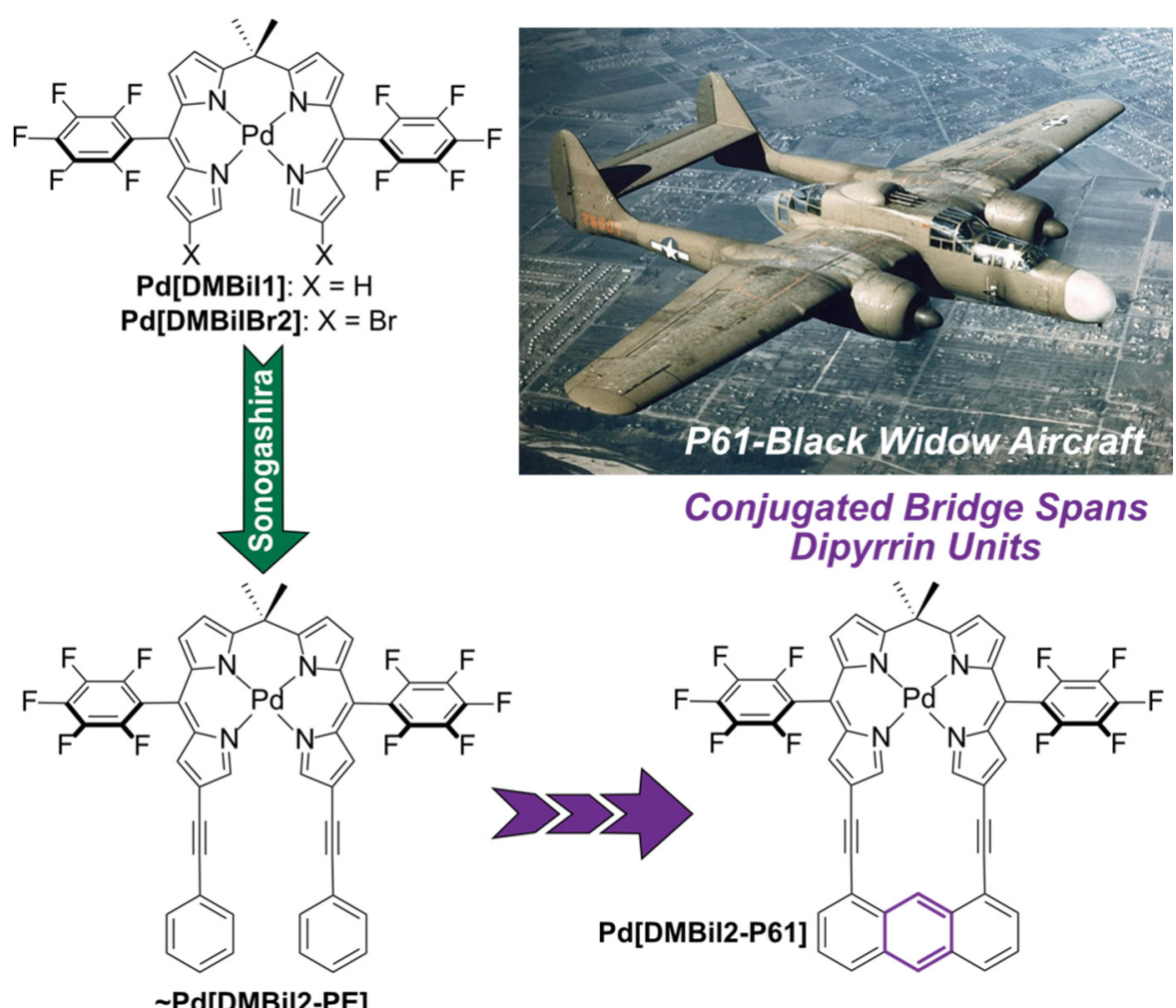

Figure 1. Conceptual strategy to target an extended palladium biladiene complex (Pd[DMBil2-P61]) possessing a conjugated bridge that spans both halves of the tetrapyrrole. This biladiene construct bears structural resemblance to the P-61 Black Widow aircraft.

\section{Materials and Methods}

All reagents and solvents used for synthesis were purchased from commercial sources (i.e., Sigma, Fisher, Acros, Alfa Aesar, VWR, Oakwood Chemicals, TCI, etc.). All glassware was dried at $150{ }^{\circ} \mathrm{C}$ for at least $3 \mathrm{~h}$ prior to use. Reactions requiring an inert atmosphere were performed under nitrogen utilizing standard Schlenk techniques. Anhydrous and air free solvents were transferred into reaction vessels via syringe or cannula methods. Solvents for synthesis were of reagent grade or better. Column chromatography was performed using 43-60 mM silica gel from Silicycle. 1,8-diethynylanthracene [44], Pd[DMBil1] [37], and $\mathbf{P d}\left[\mathbf{D M B i l 1 B r}_{2}\right.$ ] [43] were each prepared using previously described methods. Spectra for newly synthesized compounds are provided in the Supplementary Materials.

\subsection{Compound Characterization}

${ }^{1} \mathrm{H},{ }^{13} \mathrm{C}$, and ${ }^{19} \mathrm{~F}$ NMR spectra were recorded at $25{ }^{\circ} \mathrm{C}$ on a Bruker $400 \mathrm{MHz}$ spectrometer with a cryogenic QNP probe. Proton and carbon spectra are referenced to the residual proton signal of the deuterated solvent $\left(\mathrm{CDCl}_{3}=\delta 7.26\right.$ for ${ }^{1} \mathrm{H}, \delta 77.16$ for $\left.{ }^{13} \mathrm{C}\right)$. Fluorine spectra are referenced to an external trifluoroacetic acid standard (TFA $=\delta-76.55$ in $\mathrm{CD}_{3} \mathrm{CN}$ ). All chemical shifts are reported in parts-per-million. High-resolution mass spectrometry analyses were performed by the Mass Spectrometry Laboratory in the Department of Chemistry and Biochemistry using High Resolution Electrospray Ionization (ESI) or Liquid Injection Field Desorption Ionization (LIFDI) Mass Spectrometry techniques.

P-61 Black Widow Biladiene Complex (Pd[DMBil-P61]). To a hot $200 \mathrm{~mL}$ oven dried Schlenk flas was added $92 \mathrm{mg}(0.10 \mathrm{mmol})$ of Pd[DMBil1Br 2 ], $12 \mathrm{mg}(0.10 \mathrm{mmol}, 10 \mathrm{~mol} \%)$ $\mathrm{Pd}\left(\mathrm{PPh}_{3}\right)_{4}, 2 \mathrm{mg}(0.10 \mathrm{mmol}, 10 \mathrm{~mol} \%) \mathrm{CuI}$, and $70 \mathrm{mg}(0.3 \mathrm{mmol})$ of 1,8-diethynylanthracene. This solid mixture was placed under vacuum for $10 \mathrm{~min}$ while it cooled to room temperature, 
after which $50 \mathrm{~mL}$ of anhydrous toluene was added by cannula transfer under nitrogen. To the resulting solution was then added $3.0 \mathrm{~mL}$ of triethylamine via syringe. The resulting reaction solution was allowed to stir for $18 \mathrm{~h}$ at $100{ }^{\circ} \mathrm{C}$ under an atmosphere of $\mathrm{N}_{2}$, after which time, the reaction was cooled to room temperature. The solution was diluted with $100 \mathrm{~mL}$ of ethyl acetate and transferred to a separatory funnel. The organic layer was washed sequentially with water and brine, and then dried over sodium sulfate. Following solvent removal via rotary evaporation the product was purified by flash chromatography on silica using $10 \%$ dichloromethane in hexanes as the eluent, to deliver $50 \mathrm{mg}$ of the desired product as a purple solid. (51\% yield) ${ }^{1} \mathrm{H}$ NMR $(600 \mathrm{MHz}$, Chloroform- $d$ ) $\delta 9.31$ (s, $1 \mathrm{H}), 8.43(\mathrm{~s}, 1 \mathrm{H}), 7.97(\mathrm{~d}, J=9.2 \mathrm{~Hz}, 1 \mathrm{H}), 7.83(\mathrm{~d}, J=1.4 \mathrm{~Hz}, 2 \mathrm{H}), 7.68(\mathrm{dd}, J=6.9,1.1 \mathrm{~Hz}$, $2 \mathrm{H}), 7.43(\mathrm{dd}, J=8.5,6.9 \mathrm{~Hz}, 2 \mathrm{H}), 6.80(\mathrm{~d}, J=1.3 \mathrm{~Hz}, 2 \mathrm{H}), 6.77(\mathrm{~d}, J=4.6 \mathrm{~Hz}, 2 \mathrm{H}), 6.66(\mathrm{~d}$, $J=4.6 \mathrm{~Hz}, 2 \mathrm{H}), 1.85$ (s, 6H). ${ }^{13} \mathrm{C} \mathrm{NMR}\left(151 \mathrm{MHz}, \mathrm{CDCl}_{3}\right) \delta 167.80,156.40,146.01,144.34$, $141.28,136.95,136.30,135.14,132.45,132.03,131.97,130.50,129.29,128.62,128.48,128.32$, $125.43,123.97,121.72,118.18,113.99,111.99,91.40,88.97,77.57,77.36,77.15,42.75,31.51 .{ }^{19} \mathrm{~F}$ NMR (565 MHz, Chloroform-d) $\delta-138.01--138.43(\mathrm{~m}, 4 \mathrm{~F}),-151.81(\mathrm{t}, J=20.8 \mathrm{~Hz}, 2 \mathrm{~F})$, $-160.57(\mathrm{td}, J=22.6,8.2 \mathrm{~Hz}, 4 \mathrm{~F})$.

\subsection{X-ray Crystallography}

Crystals of Pd[DMBil-P61] were grown by slow evaporation of saturated solutions in a 1:1 solution of dichloromethane and hexanes containing five drops of toluene at room temperature. A crystal suitable for single-crystal X-ray diffraction was selected and mounted using viscous oil onto a plastic mesh and cooled to the data collection temperature. Data were collected on a Bruker-AXS APEX II DUO CCD diffractometer with Cu-K $\alpha$ radiation $(\lambda=1.54178 \AA)$ focused with Goebel mirrors. Unit cell parameters were obtained from 48 data frames, $0.5^{\circ} \omega$, from different sections of the Ewald sphere.

The unit-cell dimensions, equivalent reflections and systematic absences in the diffraction data are consistent with $C c$, and $C 2 / c$. The centrosymmetric space group option, $C 2 / c$, yielded chemically reasonable and computationally stable results of refinement. The data were treated with multi-scan absorption corrections [45] Structures were solved using intrinsic phasing methods [46] and refined with full-matrix, least-squares procedures on $F^{2}$ [47]. A disordered, half-occupied hexane solvent molecule which could not be modeled was treated as diffused contributions using Squeeze [48]. Non-hydrogen atoms were refined with anisotropic displacement parameters. Hydrogen atoms were treated as idealized contributions with geometrically calculated positions and with $U_{i s o}$ equal to $1.2 U_{e q}\left(1.5 U_{e q}\right.$ for methyl) of the attached atom. Atomic scattering factors are contained in the SHELXTL program library. The structures have been deposited at the Cambridge Structural Database under the following CCDC depositary numbers: CCDC 2123257.

\subsection{UV-Vis Absorption Experiments}

All UV-vis absorbance spectra were collected at room temperature on a StellarNet CCD array UV-vis spectrometer using quartz cuvettes (6Q) with a $1.0 \mathrm{~cm}$ path length from Firefly Scientific. Absorption spectra were collected in methanol containing the biladiene sample at concentrations ranging from 4.0-20.0 $\mu \mathrm{M}$. A 5.0 mM stock solution of Pd[DMBil2-P61] was prepared in ethyl acetate, and diluted in methanol to make a $50 \mu \mathrm{M}$ stock solution (1:99/ethyl acetate: methanol). This stock solution was used to make the samples of varying biladiene concentration for Beers Law analysis (all of which contained less than $1 \%$ ethyl acetate in methanol).

\subsection{Emission Experiments}

Emission spectra were recorded on an automated Photon Technology International (PTI) QuantaMaser 40 fluorometer equipped with a $75 \mathrm{~W}$ xenon arc lamp, an LPS-220B lamp power supply, and a Hamamatsu R2658 photomultiplier tube. Solutions of Pd[DMBil2-P61] were prepared in nitrogen saturated toluene (within an $\mathrm{N}_{2}$-filled glove box) in varying concentrations such that the absorbance value at $500 \mathrm{~nm}$ was approximately $0.5 \mathrm{a} . \mathrm{u}$. Samples 
were excited at $\lambda_{\mathrm{ex}}=500 \mathrm{~nm}$ and emission was scanned from $\lambda_{\mathrm{em}}=515$ to $1000 \mathrm{~nm}$ using a step size of $1 \mathrm{~nm}$, an integration time of $0.25 \mathrm{~s}$. Emission spectra presented herein are averages compiled from five separate scans. Emission data was also collected following exposure of the above samples to air. The caps were removed from the cuvettes, and the spectroscopic samples were allowed to equilibrate with the atmosphere for at least $5 \mathrm{~min}$. The cuvettes were then recapped and shaken to ensure thorough mixing of the air-saturated headspace and solution. Emission scan parameters for the air saturated samples were identical to those recorded under $\mathrm{N}_{2}$.

Emission quantum yields for the samples were calculated using a solution of $\left[\mathrm{Ru}(\mathrm{bpy})_{3}\right]\left[\mathrm{PF}_{6}\right]_{2}$ in nitrogen saturated acetonitrile $\left(\Phi_{\text {ref }}=0.094\right)[49]$ as a reference. The $\left[\mathrm{Ru}(\mathrm{bpy})_{3}\right]\left[\mathrm{PF}_{6}\right]_{2}$ solution was prepared in a $1 \mathrm{~cm}$ pathlength quartz cuvette such that its absorbance at $500 \mathrm{~nm}$ was approximately 0.5 a.u. The expression below (Equation (1)) was used to determine emission quantum yields:

$$
\Phi_{s}=\Phi_{r e f}\left(\frac{I_{s}}{I_{r e f}}\right)\left(\frac{A_{r e f}}{A_{s}}\right)\left(\frac{\eta_{s}}{\eta_{r e f}}\right)^{2}
$$

where $\Phi_{s}$ and $\Phi_{r e f}$ are the emission quantum yields of the sample and the reference, respectively. $I_{S}$ and $I_{r e f}$ are the integrated emission intensities of the sample and reference. $A_{s}$ and $A_{\text {ref }}$ refer to the absorbance values recorded for the solutions at $\lambda_{\mathrm{ex}}=500 \mathrm{~nm}$. Lastly, $\eta_{s}$ and $\eta_{\text {ref }}$ are the respective solvent refractive indices for the sample and the reference.

\subsection{Singlet Oxygen Experiments}

${ }^{1} \mathrm{O}_{2}$ production was quantified by monitoring the fluorescence quenching of $1,3-$ diphenylisobenzofuran (DPBF) as a trapping agent for ${ }^{1} \mathrm{O}_{2}$ [50]. Measurements were carried out on an automated Photon Technology International (PTI) QuantaMaster 40 fluorometer equipped with a 75-W Xenon arc lamp, an LPS-220B lamp power supply and a Hammamatsu R2658 photomultiplier tube using quartz cuvettes (6Q) of $1.0 \mathrm{~cm}$ path length. from Firefly Scientific. Each cuvette contained $3.0 \mathrm{~mL}$ of methanol solution that was $10.0 \mu \mathrm{M}$ in biladiene or $10.0 \mu \mathrm{M}$ methylene blue (used as a reference, $\Phi_{\text {ref }}=0.5$ ) [51] and $25.0 \mu \mathrm{M}$ in DPBF. An additional cuvette containing only methanol and 25.0 $\mu \mathrm{M}$ DPBF was used as a control. Consumption of DPBF was monitored by observing the change in its integrated emission intensity following irradiation with light from an Intralux 9000 light source (Volpi) fitted with a $10 \mathrm{~nm}$ (fwhm) bandpass filter centered at $600 \mathrm{~nm}$ (Thor Labs, FB600-10). During the studies, each cuvette was irradiated for $5 \mathrm{~s}$ intervals for a total of $25 \mathrm{~s}$. DPBF emission spectra were obtained by exciting at $\lambda_{\mathrm{ex}}=405 \mathrm{~nm}$ and scanning from $\lambda_{\mathrm{em}}=400-600 \mathrm{~nm}$ using a step size of $1 \mathrm{~nm}$ and an integration time of $0.25 \mathrm{~s}$.

Calibration curves were generated by increasing the proportion of DPBF to the photosensitizer. Five emission spectra were collected from samples containing $10.0 \mu \mathrm{M}$ of photosensitizer and 10.0, 20.0,30.0, 40.0, or $50.0 \mu \mathrm{M}$ of DPBF. Logarithmic regression fits to the calibration data from each solution enabled the integrated emission intensity values obtained from the ${ }^{1} \mathrm{O}_{2}$ sensitization experiments to be converted into the corresponding concentrations of unreacted DPBF. A final plot of the concentration of unreacted DPBF versus irradiation time formed a straight line of slope $\mathrm{m}$, which allowed for calculation of the ${ }^{1} \mathrm{O}_{2}$ quantum yields via Equation (2):

$$
\Phi_{s}=\Phi_{r e f}\left(\frac{m_{s}}{m_{r e f}}\right)\left(\frac{\varepsilon_{r e f}}{\varepsilon_{s}}\right)
$$

where $\Phi_{s}$ and $\Phi_{r e f}$ are the ${ }^{1} \mathrm{O}_{2}$ sensitization quantum yields of the sample and the methylene blue reference, respectively; $m_{s}$ and $m_{r e f}$ are the slopes correlating to the concentration of unreacted DPBF vs. irradiation time plots for the sample and reference; and, $\varepsilon_{s}$ and $\varepsilon_{r e f}$ are the extinction coefficients for the sample and the methylene blue reference at the 
wavelength of irradiation $\left(\lambda_{\mathrm{irr}}=600 \mathrm{~nm}\right)$. All reported ${ }^{1} \mathrm{O}_{2}$ quantum yields were obtained from an average of three trials.

\section{Results and Discussion}

The route employed to prepare Pd[DMBil2-P61] is shown in Scheme 1. Briefly, Pd[DMBil1] was selectively brominated at the 2- and 18- positions using NBS to deliver $\mathbf{P d}\left[\mathbf{D M B i l 1 B r} \mathbf{B}_{2}\right.$ ] in excellent yield. This brominated biladiene was then subjected to Sonogashira coupling with 1,8-diethynylanthracene (prepared separately from 1,8-dibromoanthracene and (triisopropylsilyl)acetylene [44]) in anhydrous toluene at $100{ }^{\circ} \mathrm{C}$, using a $\mathrm{Pd}\left(\mathrm{PPh}_{3}\right)_{4} / \mathrm{CuI}$ catalyst system and triethylamine as base. The Sonogashira coupling shown in Scheme 1 yielded the desired Pd[DMBi12-P61] compound in reasonable 51\% yield. We did not observe the formation of oligomerized products formed upon addition of multiple dialkynylanthracenes moieties to a single Pd[DMBil1Br 2 ] scaffold. This result suggests that the second Sonogashira coupling required to close the cyclic Pd[DMBil2-P61] framework is fast relative to the first coupling between 1,8-diethynylanthracene and the dibromo-palladium biladiene.
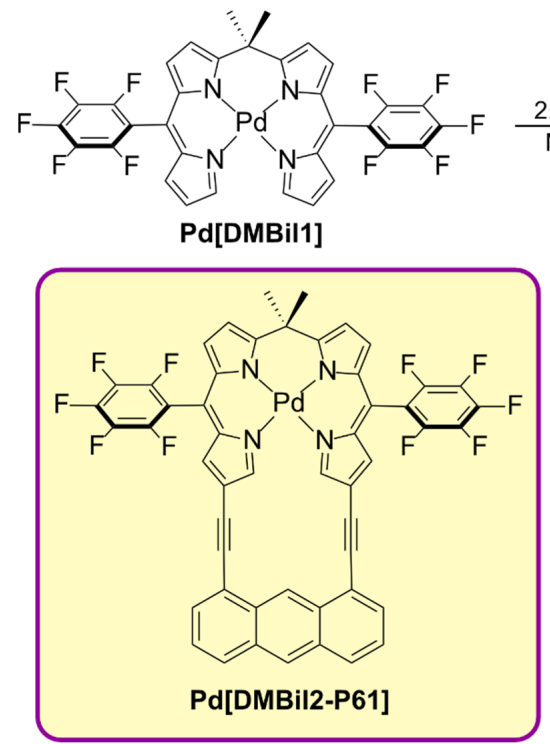

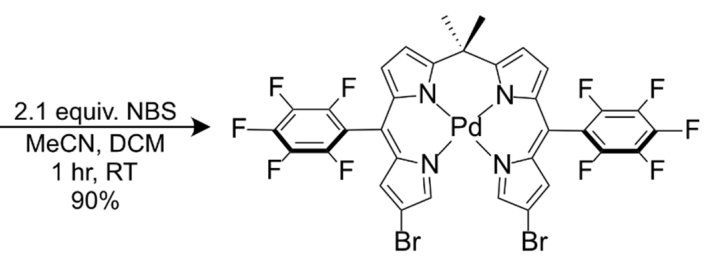

Pd[DMBilBr2]

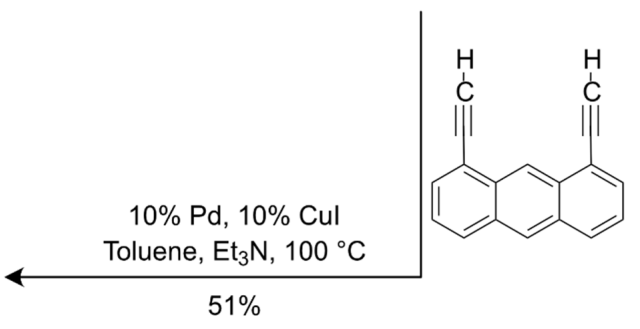

Scheme 1. Methodology employed for synthesis of Pd[DMBil2-P61].

The molecular structure of Pd[DMBil2-P61] was confirmed by single crystal X-ray diffraction studies. The molecular structure of the Black Widow inspired biladiene complex is represented in Figure 2. Despite creating a macrocyclic structure, and imparting greater rigidity to the tetrapyrrole scaffold, the $\mathrm{Pd}^{2+}$ center of $\mathbf{P d}$ [DMBil2-P61] is unable to adopt a true square planar geometry. While the coordination geometry of palladium biladiene complexes often approaches planarity, steric clashing between the $\alpha$-hydrogens at the biladiene 1- and 19-positions on the open end of the tetrapyrrole distort the geometry of the $\mathrm{Pd}-\mathrm{N}_{4}$ core. From a more quantitative standpoint, the geometry index for $\mathrm{Pd}-\mathrm{N}_{4}$ coordination of Pd[DMBil2-P61] was determined to $\tau_{4}^{\prime}=0.1681$ [32,52], which is the most distorted from square planar (and toward tetrahedral) of any palladium biladiene complex that has been structurally characterized to date. By contrast, the parent Pd[DMBil1] complex presents a geometry index of $\tau^{\prime}{ }_{4}=0.109$, while other dialkyne appended palladium biladiene complexes displayed geometry indices of $\tau^{\prime}{ }_{4} \sim 0.114-0.135$. The average $\mathrm{Pd}-\mathrm{N}$ bond distances for Pd[DMBil2-P61] were determined to be $2.018 \AA$, which are very similar to those observed for Pd[DMBil1] and other extended biladiene frameworks. 

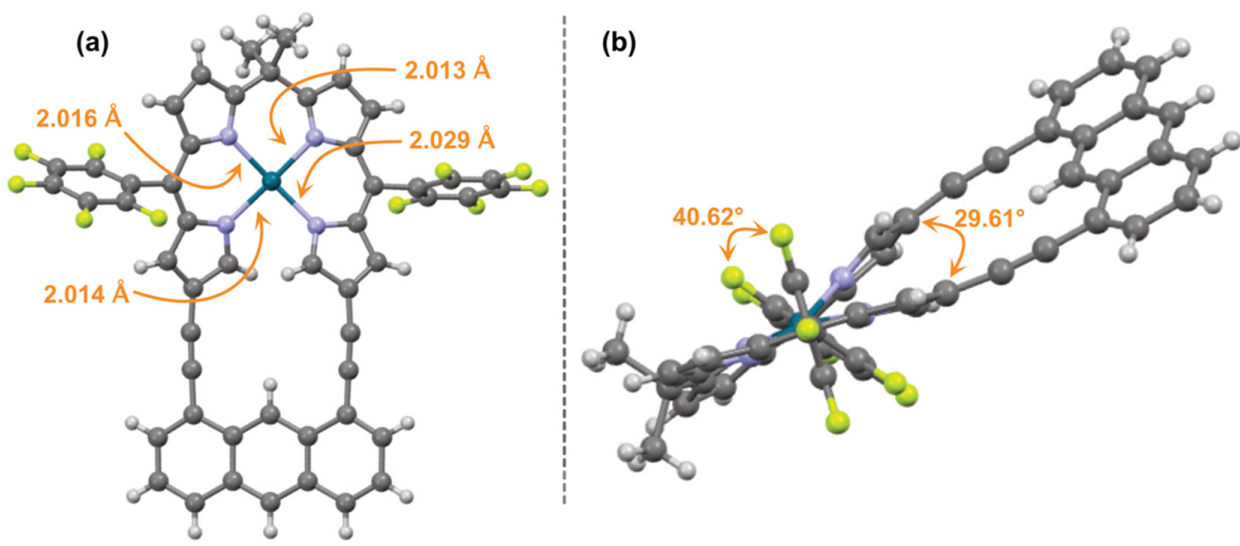

Figure 2. Solid-state structure of Pd[DMBil2-P61] shown (a) face on and (b) in profile. Several bonding metrics are highlighted in orange.

Upon completing the synthesis and characterization of Pd[DMBil2-P61], we characterized the steady state photochemical and spectroscopic properties of this macrocyclic system. The UV-Vis absorption spectrum for Pd[DMBil2-P61] was recorded in methanol, and is shown in Figure $3 a$ against those of $\mathbf{P d}[\mathrm{DMBil1}]$ and a previously reported extended biladiene bearing aryl-alkyne groups at the 2- and 18-positions (Pd[DMBil2-PE]). The extended $\pi$-system of Pd[DMBil2-P61] effectively pushes this compound's light harvesting abilities past those displayed by the parent Pd[DMBil1] complex. More specifically, Pd[DMBil2-P61] absorbs light in the phototherapeutic window to wavelengths as long as $\sim 650 \mathrm{~nm}$ and also displays a second strong absorption feature toward the high energy end of the visible region. The main absorption feature is centered at $\lambda_{\max }=520 \mathrm{~nm}\left(\varepsilon=43,600 \mathrm{M}^{-1} \mathrm{~cm}^{-1}\right)$ and the weaker local maximum is centered at $437 \mathrm{~nm}\left(\varepsilon_{437}=30,000 \mathrm{M}^{-1} \mathrm{~cm}^{-1}\right)$.
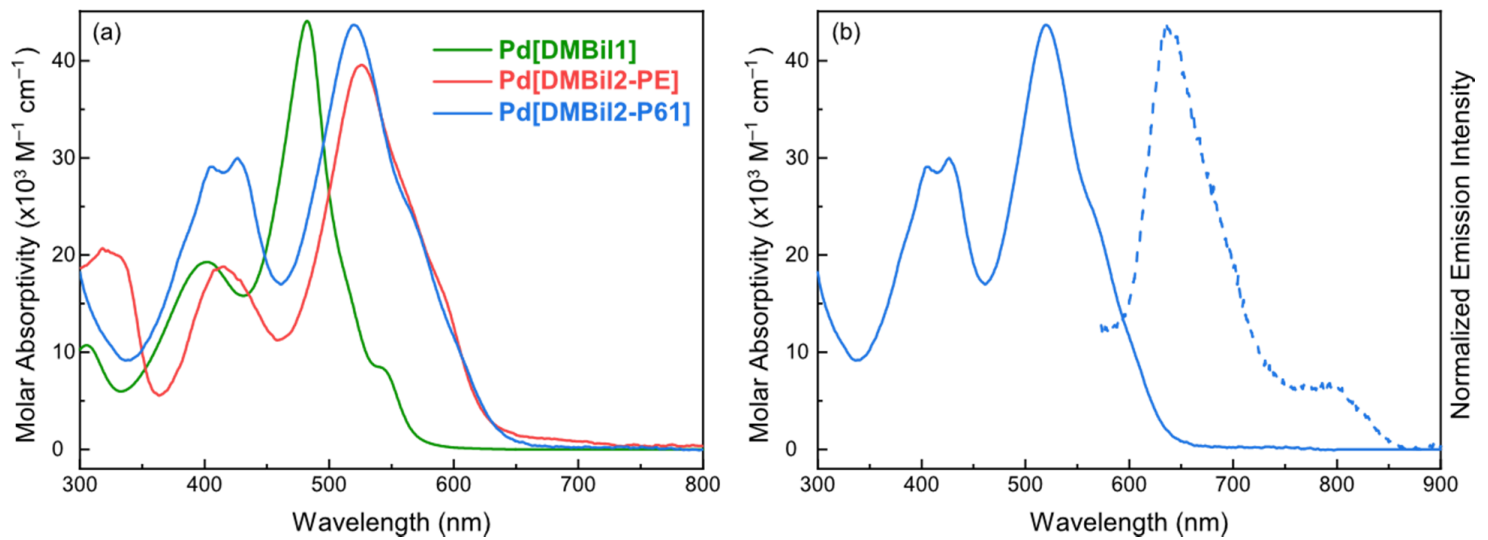

Figure 3. Steady-state spectroscopic properties of Pd[DMBil2-P61]. (a) Comparison of the UV-vis absorbance properties of Pd[DMBil1], Pd[DMBil2-PE], and Pd[DMBil2-P61] in MeOH. (b) UV-vis absorption spectrum (solid-trace) juxtaposed against the normalized luminescence profile recorded for Pd[DMBil2-P61] in toluene under $\mathrm{N}_{2}$.

Pd[DMBil2-P61] displays attractive light absorption properties for PDT applications as compared to the parent palladium biladiene (Pd[DMBil1]), which does not absorb light in the phototherapeutic window. Comparisons between Pd[DMBil2-P61] and a previously reported extended biladiene derivative (Pd[DMBil2-PE]), akin to that shown on the bottom left of Figure 1, are more nuanced. While the overall shape and absorbance profile of Pd[DMBil2-P61] is nearly identical to that of Pd[DMBil2-PE] (see Figure 3a), the new Black Widow inspired construct does absorb slightly more strongly at its maximum $\left(\varepsilon_{\max }=43,600 \mathrm{M}^{-1} \mathrm{~cm}^{-1}\right.$ for Pd[DMBil2-P61]; $\left(\varepsilon_{\max }=40,900 \mathrm{M}^{-1} \mathrm{~cm}^{-1}\right.$ for Pd[DMBil2-PE]). In addition, Pd[DMBil2-P61] also displays a significantly stronger 
absorption feature toward the high energy end of the visible region compared to both Pd[DMBil1] $\left(\varepsilon_{402}=19,280 \mathrm{M}^{-1} \mathrm{~cm}^{-1}\right)$ and Pd[DMBil2-PE] $\left(\varepsilon_{414}=18,300 \mathrm{M}^{-1} \mathrm{~cm}^{-1}\right)$. We attribute this increase in absorptivity from $\sim 350-450 \mathrm{~nm}$ to the larger conjugated anthracene bridge of Pd[DMBil2-P61], in contrast to the two independent aryl-alkyne units present for Pd[DMBil2-PE].

Previous studies of Pd[DMBil1] have shown that this tetrapyrrole supports a triplet photochemistry and dual emission profiles (i.e., both singlet and triplet emission) [37], and the emission properties of Pd[DMBil2-P61] were probed in $\mathrm{N}_{2}$ saturated toluene. We note that toluene was specifically employed for photoluminescence spectroscopy experiments to avoid aggregation of the extended biladiene architecture in solution. As shown in Figure 3b, Pd[DMBil2-P61] displays a main fluorescence feature centered at $\lambda_{\mathrm{fl}}=638 \mathrm{~nm}$. Phosphorescence was also observed as a plateau that spans from $\lambda_{\mathrm{em}}=750-850 \mathrm{~nm}$. Upon exposure of the Pd[DMBil2-P61] sample to air, this longer wavelength luminescence was completely quenched (Figure S4), consistent with this feature corresponding to emission from a triplet excited state. Like other previously studied palladium biladiene derivatives, Pd[DMBil2-P61] is weakly luminescent, displaying fluorescence and phosphorescence quantum yields of $\Phi_{\mathrm{Fl}}=3.22 \times 10^{-4}$ and $\Phi_{\mathrm{Ph}}=5.09 \times 10^{-5}$, respectively. These values are very similar to those recorded for Pd[DMBil1] as well as other $\mathrm{Pd}^{2+}$ containing biladienes.

The observation that the long-wavelength luminescence observed for Pd[DMBil2-P61] is quenched in the presence of air (vide supra), suggests that the triplet excited-state of this biladiene can be deactivated via energy transfer to molecular oxygen. Accordingly, we evaluated the efficacy with which Pd[DMBil2-P61] sensitizes the formation of ${ }^{1} \mathrm{O}_{2}$ to assess its potential for use as a PDT agent. Based on prior work, both Pd[DMBil1] $\left(\Phi_{\Delta}=0.54\right)$ and Pd[DMBil2-PE] $\left(\Phi_{\Delta}=0.59\right)$ can sensitize the generation of singlet oxygen with reasonable efficiencies for photomedical applications when irradiated at $\lambda_{\mathrm{ex}}=500$ or 600 nm, respectively. Repetition of such studies for Pd[DMBil2-P61] using methylene blue as an actinometer $\left(\Phi_{\Delta}=50 \%\right)$ and 1,3-diphenylisobenzofuran (DPBF) as a ${ }^{1} \mathrm{O}_{2}$ trapping agent [50] demonstrated that the Black Widow inspired biladiene construct is a potent triplet photosensitizer. Upon irradiation at $\lambda_{\mathrm{ex}}=600 \mathrm{~nm}, \mathbf{P d}[\mathrm{DMBil2}-\mathbf{P 6 1}]$ was determined to generate singlet oxygen with nearly $85 \%$ efficiency $\left(\Phi_{\Delta}=0.84( \pm 0.01)\right)$, marking this complex as the most potent biladiene-based ${ }^{1} \mathrm{O}_{2}$ sensitizer that has been developed to date.

The heightened efficacy with which the Black Widow inspired biladiene generates singlet oxygen is particularly impressive when compared against the aryl-alkyne appended biladiene (Pd[DMBil2-PE]), which is $~ 25 \%$ less efficient at sensitizing the formation of ${ }^{1} \mathrm{O}_{2}$ upon excitation at $600 \mathrm{~nm}$. The improved quantum yield that is realized upon linking both alkyne appendages via the anthracene bridge of Pd[DMBil2-P61] may be attributed to the heightened rigidity of the macrocyclic architecture (over Pd[DMBil2-PE]). Since the luminescence efficiency of Pd[DMBil2-P61] is very similar to more structurally flexible biladienes that have been previously studied, it is likely that the more rigid anthracene bridged dialkynyl biladiene photosensitizer undergoes vibrational relaxation from the triplet excited state more slowly than other $\mathrm{Pd}^{2+}$ biladienes that have been previously considered. The ability of the rigid Pd[DMBil2-P61] biladiene construct to absorb light in the phototherapeutic window and sensitize the formation of ${ }^{1} \mathrm{O}_{2}$ with a quantum yield of $\sim 85 \%$ highlights the potential of this compound for evaluation as an PDT agent. We note that Pd[DMBil2-P61] sensitizes the formation of ${ }^{1} \mathrm{O}_{2}$ with efficiencies that rival some of the best porphyrinoid based photosensitizers that have been clinically evaluated as agents of PDT, including Photofrin $\left(\Phi_{\Delta}=89 \%\right)$, Foscan $\left(\Phi_{\Delta}=87 \%\right)$, Laserphyrin $\left(\Phi_{\Delta}=77 \%\right)$, Tookad $\left(\Phi_{\Delta}=50 \%\right)$, Redaporphine $\left(\Phi_{\Delta}=43 \%\right)$, and Photosens $\left(\Phi_{\Delta}=38 \%\right)$ [53-56].

\section{Conclusions and Future Directions}

Photodynamic therapy (PDT) holds significant potential as an alternative treatment option for a variety of different cancers and other disease states. To date, much work has been dedicated to the development of new agents for PDT that absorb strongly in the phototherapeutic window and generate significant amounts of singlet oxygen. We have 
previously reported that biladienes are oligotetrapyrroles that upon coordination to $\mathrm{Pd}^{2+}$ can serve as biocompatible agents of PDT toward triple negative breast cancer cells. While the parent Pd[DMBil1] architecture displays a reasonable ${ }^{1} \mathrm{O}_{2}$ quantum yield of $\Phi_{\Delta}=0.54$, it must be activated using $500 \mathrm{~nm}$ light, which is outside the phototherapeutic window that most deeply penetrates biological tissues.

Synthetic modification of Pd[DMBil1] via introduction of alkynes at the 2- and 18-positions effectively shifts the absorbance profile for this architecture toward the low energy end of the visible region. To this end, a new biladiene framework (Pd[DMBil2-P61]), the structure of which was inspired by the P-61 Black Widow patrol aircraft, places an anthracene bridge across the two alkynes and effectively absorbs light from 600-650 nm. X-ray crystallography confirms the macrocyclic nature of the Pd biladiene complex, which maintains a pseudo-square planar geometry about the metal center. Most notably, in addition to absorbing light capable of penetrating epithelial tissues, Pd[DMBil2-P61] also demonstrated a drastic increase in singlet oxygen generation quantum yield $\left(\Phi_{\Delta}=0.84\right)$ compared to previously reported $\mathrm{Pd}^{2+}$ biladienes, including those that bear unbridged alkynyl units. When all of these characteristics are taken into consideration, the Black Widow inspired biladiene complex (Pd[DMBil2-P61]) emerges as an attractive candidate for further consideration and study as a potential phototherapeutic agent. We anticipate that future efforts to employ this (and related) biladiene phototherapeutics will require PEGylation of the tetrapyrrole periphery for enhanced solubilization in biological media [40-42]. Solubilized biladiene agents will be evaluated for in-vitro efficacy and dark toxicity against various cell lines in culture, and in vivo efficacy using murine tumor models.

The development of Pd[DMBil2-P61] opens doors to many different research directions going forward. Future efforts in our laboratory will focus on synthetically modifying the anthracene bridge of Pd[DMBil2-P61] to further improve the compound's light absorbing properties in the phototherapeutic window and map the impact that such alterations have on the biladiene's excited state dynamics. We expect that such efforts may lead to next generation Black Widow inspired PDT agents that can absorb toward the near-IR, while maintaining exceptionally high quantum yields for singlet oxygen sensitization. Our work along these lines will be disclosed in due course.

Supplementary Materials: The following supporting information can be downloaded at: https:// www.mdpi.com/article/10.3390/photochem2010005/s1, Crystallographic and spectroscopic data. Crystallographic data are also available from the Cambridge Crystallographic Data Centre (CCDC 2123257).

Author Contributions: Conceptualization, A.T.R. and J.R.; Investigation, A.T.R. and J.R.; Crystallography, G.P.A.Y.; Writing the original draft, A.T.R.; Writing—Review and editing, A.T.R. and J.R.; Funding acquisition, J.R. All authors have read and agreed to the published version of the manuscript.

Funding: This research was supported by the U.S. Department of Energy, Office of Science, Office of Basic Energy Sciences EPSCoR and Catalysis programs under award no. DESC-0001234.

Institutional Review Board Statement: Not applicable.

Informed Consent Statement: Not applicable.

Data Availability Statement: The data presented in this study are available in the supplementary material.

Acknowledgments: This manuscript is dedicated to David I. Schuster, Professor Emeritus, New York University and Vincent Giglio who worked at Northrop Grumman (manufacturer of the P-61 Black Widow) during the 1990s. Schuster ignited J.R.'s passion for synthesis and photochemistry and Giglio helped shape J.R.'s curiosity, work ethic, and love of learning. This research was supported by the U.S. Department of Energy, Office of Science, Office of Basic Energy Sciences EPSCoR and Catalysis programs under award no. DESC-0001234. We thank M.I. Martin for preliminary efforts to obtain and solve $\mathrm{X}$-ray diffraction data.

Conflicts of Interest: The authors declare no conflict of interest.

Sample Availability: Samples of the compounds are not available from the authors. 


\section{References}

1. Ferreira dos Dantos, A.; Queiroz de Almeida, D.R.; Ferriera Terra, L.; Baptista, M.S.; Labriola, L. Photodynamic therapy in cancer treatment-An update review. J. Cancer Metastasis Treat. 2019, 5, 25.

2. Dolmans, D.; Fukumura, D.; Jain, R. Photodynamic therapy for cancer. Nat. Rev. Cancer 2003, 3, 380-387. [CrossRef] [PubMed]

3. Dougherty, T.J.; Gomer, C.J.; Henderson, B.W.; Jori, G.; Kessel, D.; Korbelik, M.; Moan, J.; Peng, Q. Photodynamic Therapy. JNCI J. Natl. Cancer Inst. 1998, 90, 889-905. [CrossRef] [PubMed]

4. $\quad$ Dougherty, T.J.; Marcus, S.L. Photodynamic therapy. Eur. J. Cancer 1992, 28, 1734-1742. [CrossRef]

5. Miller, J. Photodynamic Therapy: The Sensitization of Cancer Cells to Light. J. Chem. Educ. 1999, 76, 592-594. [CrossRef]

6. Castano, A.P.; Demidova, T.N.; Hamblin, M.R. Mechanisms in photodynamic therapy: Part one—Photosensitizers, photochemistry and cellular localization. Photodiagnosis Photodyn. Ther. 2004, 1, 279-293. [CrossRef]

7. Agostinis, P.; Berg, K.; Cengel, K.A.; Foster, T.H.; Girotti, A.W.; Gollnick, S.O.; Hahn, S.M.; Hamblin, M.R.; Juzeniene, A.; Kessel, D.; et al. Photodynamic therapy of cancer: An update. CA A Cancer J. Clin. 2011, 61, 250-281. [CrossRef]

8. DeRosa, M.C.; Crutchley, R.J. Photosensitized singlet oxygen and its applications. Coord. Chem. Rev. 2002, 233-234, 351-371. [CrossRef]

9. Macdonald, I.J.; Dougherty, T.J. Basic principles of photodynamic therapy. J. Porphyr. Phthalocyanines 2001, 5, 105-129. [CrossRef]

10. Robertson, C.A.; Hawkins Evans, D.; Abrahamse, H. Photodynamic therapy (PDT): A short review on cellular mechanisms and cancer research applications for PDT. J. Photochem. Photobiol. B Biol. 2009, 96, 1-8. [CrossRef]

11. Abrahamse, H.; Hamblin, M.R. New photosensitizers for photodynamic therapy. Biochem. J. 2016, 473, 347-364. [CrossRef] [PubMed]

12. Hamblin, M.R. Photodynamic Therapy for Cancer: What's Past Is Prologue. Photochem. Photobiol. 2020, 96, 506-516. [CrossRef] [PubMed]

13. Algorri, J.F.; Ochoa, M.; Roldán-Varona, P.; Rodríguez-Cobo, L.; López-Higuera, J.M. Photo-dynamic Therapy: A Compendium of Latest Reviews. Cancers 2021, 13, 4447. [CrossRef]

14. Abdelkarim-Elafifi, H.; Parada-Avendaño, I.; Arnabat-Dominguez, J. Photodynamic Therapy in Endodontics: A Helpful Tool to Combat Antibiotic Resistance? A Literature Review. Antibiotics 2021, 10, 1106. [CrossRef]

15. Lotufo, M.A.; Tempestini Horliana, A.C.R.; Santana, T.; de Queiroz, A.C.; Gomes, A.O.; Motta, L.J.; Ferrari, R.A.M.; dos Santos Fernandes, K.P.; Bussadori, S.K. Efficacy of Photodynamic Therapy on the Treatment of Herpes Labialis: A Systematic Review. Photodiagnosis Photodyn. Ther. 2020, 29, 101536. [CrossRef]

16. Conrado, P.C.V.; Sakita, K.M.; Arita, G.S.; Galinari, C.B.; Gonçalves, R.S.; Lopes, L.D.G.; Lonardoni, M.V.C.; Teixeira, J.J.V.; Bonfim-Mendonça, P.S.; Kioshima, E.S. A Systematic Review of Photodynamic Therapy as an Antiviral Treatment: Potential Guidance for Dealing with SARS-CoV-2. Photodiagnosis Photodyn. Ther. 2021, 34, 102221. [CrossRef] [PubMed]

17. Tosa, M.; Ogawa, R. Photodynamic Therapy for Keloids and Hypertrophic Scars: A Review. Scars Burn. Heal. 2020, 6, 1-8. [CrossRef]

18. Nyman, E.S.; Hynninen, P.H. Research advances in the use of tetrapyrrolic photosensitizers for photodynamic therapy. $J$. Photochem. Photobiol. B Biol. 2004, 73, 1-28. [CrossRef]

19. Diwu, Z.; Lown, J.W. Phototherapeutic potential of alternative photosensitizers to porphyrins. Pharmacol. Ther. 1994, 63, 1-35. [CrossRef]

20. Dabrowski, J.M.; Pucelik, B.; Regiel-Futyra, A.; Brindell, M.; Mazuryk, O.; Kyziol, A.; Stochel, G.; Macyk, W.; Arnaut, L.G. Engineering of relevant photodynamic processes through structural modifications of metallotetrapyrrolic photosensitizers. Coord. Chem. Rev. 2016, 325, 67-101. [CrossRef]

21. Pistner, A.J.; Yap, G.P.; Rosenthal, J. A Tetrapyrrole Macrocycle Displaying a Multielectron Redox Chemistry and Tunable Absorbance Profile. J. Phys. Chem. C 2012, 32, 16918-16924. [CrossRef]

22. Pistner, A.J.; Lutterman, D.A.; Ghidiu, M.J.; Ma, Y.Z.; Rosenthal, J. Synthesis, electrochemistry, and photophysics of a family of phlorin macrocycles that display cooperative fluoride binding. J. Am. Chem. Soc. 2013, 17, 6601-6607. [CrossRef]

23. O'Brien, A.Y.; McGann, J.P.; Geier, G.R., III. Dipyrromethane + dipyrromethanedicarbinol routes to an electron deficient mesosubstituted phlorin with enhanced stability. J. Org. Chem. 2007, 11, 4084-4092. [CrossRef]

24. Pistner, A.J.; Lutterman, D.A.; Ghidiu, M.J.; Walker, E.; Yap, G.P.A.; Rosenthal, J. Factors Controlling the Spectroscopic Properties and Supramolecular Chemistry of an Electron Deficient 5,5-Dimethylphlorin Architecture. J. Phys. Chem. C 2014, 118, 14124-14132. [CrossRef] [PubMed]

25. Kim, D.; Chun, H.-J.; Donnelly, C.C.; Geier, G.R., III. Two-Step, One-Flask Synthesis of a Me-so-Substituted Phlorin. J. Org. Chem. 2016, 81, 5021-5031. [CrossRef]

26. Bruce, A.M.; Weyburne, E.S.; Engle, J.T.; Ziegler, C.J.; Geier, G.R., III. Phlorins Bearing Different Substituents at the sp3-Hybridized Meso-Position. J. Org. Chem. 2014, 79, 5664-5672. [CrossRef] [PubMed]

27. LeSaulnier, T.D.; Graham, B.W.; Geier, G.R., III. Enhancement of Phlorin Stability by the In-corporation of meso-Mesityl Substituents. Tetrahedron Lett. 2005, 46, 5633-5637. [CrossRef]

28. Nieto-Pescador, J.; Abraham, B.; Pistner, A.J.; Rosenthal, J.; Gundlach, L. Electronic State Dependence of Heterogeneous Electron Transfer: Injection from the S 1 and S 2 State of Phlorin into $\mathrm{TiO}_{2}$. Phys. Chem. Chem. Phys. 2015, 17, 7914-7923. [CrossRef]

29. Pistner, A.J.; Martin, M.I.; Yap, G.P.A.; Rosenthal, J. Synthesis, structure, electronic characterization and halogenation of gold(III) phlorin complexes. J. Porphyr. Phthalocyanines 2021, 25, 683-695. [CrossRef] 
30. Flint, D.L.; Fowler, R.L.; LeSaulnier, T.D.; Long, A.C.; O’Brien, A.Y.; Geier, G.R., III. Investigation of Complementary Reactions of a Dipyrromethane with a Dipyrromethanemonocarbinol Leading to a 5-Isocorrole. J. Org. Chem. 2010, 75, 553-563. [CrossRef] [PubMed]

31. Costa, R.; Geier, G.R., III; Ziegler, C.J. Structure and Spectroscopic Characterization of Free Base and Metal Complexes of 5,5-Dimethyl-10,15-Bis(Pentafluorophenyl)Isocorrole. Dalton Trans. 2011, 40, 4384-4386. [CrossRef]

32. Hoffmann, M.; Cordes, B.; Kleeberg, C.; Schweyen, P.; Wolfram, B.; Broring, M. Template Synthesis of Alkyl-Substituted Metal Isocorroles. Eur. J. Inorg. Chem. 2016, 19, 3076-3085. [CrossRef]

33. Pomarico, G.; Xiao, X.; Nardis, S.; Paolesse, R.; Fronczek, F.R.; Smith, K.M.; Fang, Y.; Ou, Z.; Kadish, K.M. Synthesis and characterization of free-base, copper, and nickel isocorroles. Inorg. Chem. 2010, 12, 5766-5774. [CrossRef]

34. Thomas, K.E.; Beavers, C.M.; Gagnon, K.J.; Ghosh, A. beta-Octabromo- and beta-Octakis(trifluoromethyl)isocorroles: New Sterically Constrained Macrocyclic Ligands. ChemistryOpen 2017, 3, 402-409. [CrossRef]

35. Martin, M.I.; Cai, Q.; Yap, G.P.A.; Rosenthal, J. Synthesis, Redox, and Spectroscopic Proper-ties of Pd(II) 10,10-Dimethylisocorrole Complexes Prepared via Bromination of Dimethylbila-diene Oligotetrapyrroles. Inorg. Chem. 2020, 59, 18241-18252. [CrossRef] [PubMed]

36. Pistner, A.J.; Pupillo, R.C.; Yap, G.P.A.; Lutterman, D.A.; Ma, Y.Z.; Rosenthal, J. Electro-chemical, Spectroscopic and Singlet Oxygen Sensitization Characteristics of 10,10-Dimethylbiladiene Complexes of Zinc and Copper. J. Phys. Chem A 2014, 118, 10639-10648. [CrossRef]

37. Potocny, A.; Pistner, A.; Yap, G.; Rosenthal, J. Electrochemical, Spectroscopic, and 1O2 Sensi-tization Characteristics of Synthetically Accessible Linear Tetrapyrrole Complexes of Palladium and Platinum. Inorg. Chem. 2017, 56, 12703-12711. [CrossRef] [PubMed]

38. Clara De Simone, B.; Mazzone, G.; Russo, N.; Sicilia, E.; Toscano, M. Metal Atom Effect on the Photophysical Properties of Mg(II), $\mathrm{Zn}(\mathrm{II}), \mathrm{Cd}(\mathrm{II})$, and Pd(II) Tetraphenylporphyrin Complexes Proposed as Possible Drugs in Photodynamic Therapy. Molecules 2016, 21, 1093.

39. Cai, Q.; Rice, A.T.; Pointer, C.A.; Martin, M.I.; Davies, B.; Yu, A.; Ward, K.; Hertler, P.R.; Warndorf, M.C.; Yap, G.P.A.; et al. Synthesis, Electrochemistry and Photophysics of Pd(II) Biladiene Complexes Bearing Varied Substituents at the sp3-Hybridized 10-Position. Inorg. Chem. 2021, 60, 15797-15807. [CrossRef]

40. Potocny, A.; Riley, R.; O'Sullivan, R.; Day, E.; Rosenthal, J. Photochemotherapeutic Properties of a Linear Tetrapyrrole Palladium (II) Complex displaying an Exceptionally High Phototoxicity Index. Inorg. Chem. 2018, 57, 10608-10615. [CrossRef]

41. Riley, R.S.; O'Sullivan, R.K.; Potocny, A.M.; Rosenthal, J.; Day, E.S. Evaluating Nanoshells and a Potent Biladiene Photosensitizer for Dual Photothermal and Photodynamic Therapy of Triple Negative Breast Cancer Cells. Nanomaterials 2018, 8, 658. [CrossRef] [PubMed]

42. Wang, J.; Potocny, A.M.; Rosenthal, J.; Day, E.S. Upconverting Gold Nanoshell- Linear Tetrapyrrole Conjugates for Near Infrared-Activated Dual Photodynamic and Photothermal Therapies. ACS Omega 2020, 5, 926-940. [CrossRef]

43. Rice, A.T.; Martin, M.I.; Warndorf, M.C.; Yap, G.P.A.; Rosenthal, J. Synthesis, Spectroscopic and $1 \mathrm{O} 2$ Sensitization Characteristics of Extended Pd(II) 10,10-Dimethylbiladiene Complexes Bearing Alkynyl-Aryl Appendages. Inorg. Chem. 2021, 60, 11154-11163. [CrossRef] [PubMed]

44. Albrecht, F.; Rey, D.; Fatayer, S.; Schulz, F.; Perez, D.; Pena, D.; Gross, L. Intramolecular Coupling of Terminal Alkynes by Atom Manipulation. Angew. Chem. Int. Ed. 2020, 59, 22989-22993. [CrossRef] [PubMed]

45. Apex3 [Computer Software]; Bruker AXS Inc.: Madison, WI, USA, 2015.

46. Sheldrick, G.M. SHELXT-Integrated space-group and crystal-structure determination. Acta Cryst. 2015, A71, 3-8. [CrossRef] [PubMed]

47. Sheldrick, G.M. Crystal structure refinement with SHELXL. Acta Cryst. 2015, C71, 3-8.

48. Spek, A.L. Chemistry and structure in Acta Crystallographica Section C. Acta Cryst. 2015, C71, 9-18.

49. Brouwer, A. Standards for Photoluminescence Quantum Yield Measurements in Solution. Pure Appl. Chem. 2011, 83, 2213-2228. [CrossRef]

50. Singh, A.; McIntyre, N.; Koroll, G. Photochemical Formation of Metastable Species from 1,3-Diphenylisobenzofuran. Photochem. Photobiol. 1978, 28, 595-601. [CrossRef]

51. Tanielian, C.; Wolff, C. Determination of the parameters controlling singlet oxygen production via oxygen heavy-atom enhancement of triplet yields. J. Phys. Chem. 1995, 99, 9831-9837. [CrossRef]

52. Okuniewski, A.; Rosiak, D.; Chojnacki, J.; Becker, B. Coordination Polymers and Molecular Structures Among Complexes of Mercury(II) Halides with Selected 1-Benzoylthioureas. Polyhedron 2015, 90, 47-57. [CrossRef]

53. Ormond, A.B.; Freeman, H.S. Dye Sensitizers for Photodynamic Therapy. Materials 2013, 6, 3817-3840. [CrossRef] [PubMed]

54. Correia, J.H.; Rodrigues, J.A.; Pimenta, S.; Dong, T.; Yang, Z. Photodynamic Therapy Review: Principles, Photosensitizers, Applications, and Future Directions. Pharmaceutics 2021, 13, 1332. [CrossRef] [PubMed]

55. Bonnett, R. Photosensitizers of the Porphyrin and Phthalocyanine Series for Photodynamic Therapy. Chem. Soc. Rev. 1995, 24, 19-33. [CrossRef]

56. Pham, T.C.; Nguyen, V.-N.; Choi, Y.; Lee, S.; Yoon, J. Recent Strategies to Develop Innovative Photosensitizers for Enhanced Photodynamic Therapy. Chem. Rev. 2021, 121, 13454-13619. [CrossRef] [PubMed] 